\title{
CASE OF CHOLECYSTOTOMY.
}

By W A LTER G. SM I TH, M.D.;

Physician to Sir P. Dun's Hospital ;

AND

CHARLES B. BALL, M.D. ;

Surgeon to Sir P. Dun's Hospital.

[Read in the Section of Medicine, May 17, 1889.]

Upon the 27th of February, 1889, Dr. Walter Smith was asked to see Mrs. R_- with Dr. Kough, of Monkstown. The lady was on a visit to her mother, and had been in fair health until a few days previously.

On the evening of Monday, February 25th, Dr. Kough was summoned to the patient, on account of violent pain which had attacked her across the upper part of the abdomen. This was apparently due to a fit of indigestion, following a hurried meal of cold meat.

Dr. Kough prescribed accordingly, and next day he heard that she was better, but required an aperient, and he ordered a dose of castor-oil.

He was, however, again sent for on Wednesday morning, and found her looking very ill and anxious, and suffering from intense abdominal pain. The pulse was quiet, and she was free from pyrexia.

Examining the abdomen, Dr. Kough detected a small tumour below the right ribs, and in the afternoon of that day Dr. Smith visited the lady with him.

Her condition then was as follows:-She was cheerful and bright, but in evident suffering. The abdomen was not distended, and readily lent itself to examination, there being no rigidity and no accumulation of fat. The only hindrance was a patch of extreme tenderness between the umbilicus and the ribs on the right side. 
Here a slight localised projection was visible, and by gentle palpation a tumour could easily be felt.

The tumour was rounded, directed vertically downwards for about $2 \frac{1}{2}$ inches, tense, and excessively tender. It shifted up and down distinctly with the respiratory movements, and could be swayed from side to side beneath the abdominal parietes. The surface was smooth and free from inequalities in form or consistence, and fluctuation could not be made out. There was no jaundice, and the motions were of natural appearance. The temperature was normal.

After due consideration it was thought probable that the tumour was an inflamed and distended gall-bladder, caused by obstruction of the cystic duct, possibly by gall-stones.

This view was based chiefly upon the situation, cylindrical form, projection forwards, and mobility of the tumour, and was strengthened by the sex of the patient and by the reflection that it was difficult to account otherwise for the phenomena. Seeing that the patient had become rapidly worse, and in the face of the probability, if not certainty, of disastrous consequences ensuing upon delay or expectant treatment, the propriety of an exploratory incision was suggested, and a surgical consultation was proposed.

Dr. C. Ball saw her next day with us, and agreed that it was a suitable case in which to operate.

The lady's husband was telegraphed for, and the operation was performed on Friday, March 1st, by Dr. Ball.

As soon as the patient was under the influence of ether the details of the tumour were more fully made out; it extended from the cartilage of the 10th rib to about $\frac{3}{4}$ of an inch to the left of and below the umbilicus; it was pear-shaped, and had a considerable amount of lateral motion, but was attached above so that it could be swayed backwards and forwards like a pendulum. An incision $1 \frac{1}{2}$ inches long was made in the linea alba above the umbilicus, and the tumour was explored with the finger; it was found to be a distended gall-bladder with recent adhesions to the surrounding structures.

The fundus was with a little difficulty brought into the wound; it was deeply congested; flakes of lymph were adherent to it, and 
the omentum was attached to it by soft recent adhesions. The omentum was detached, and the peritoneum packed round the tumour with flat sponges; a hydrocele trochar was now introduced and exit given to about $6 \mathrm{oz}$. of whitish viscid fluid devoid of bile. The opening was enlarged, and a finger introduced, which passed along the dilated cystic duct, but was unable to appreciate the cause of the obstruction. 7 small gall-stones were found free in the cavity, and also a quantity of white putty-like material. The cavity of the gall-bladder was thoroughly cleansed, and it was then seen that the mucous membrane was greatly inflamed, being of a deep maroon colour. The wound in the gall-bladder was carefully sutured to the lower part of the incision, and the upper portion closed by deep sutures. A large-sized flanged drainage tube was left in the gall-bladder, and dry dressings applied. March 2ndThere has only been a little oozing of bloody serum from the wound, but rather copious bilious vomiting. Drainage tube removed. March 3rd-Bile is being discharged copiously from the wound, March 4th-Still discharging bile. A careful search with probe and scoop failed to detect a calculus, but a plug as big as the top of the little finger was removed, formed apparently of inspissated mucus. March 5th-Discharge of bile almost ceased. From this date the wound rapidly healed, and by the 15 th day the opening in the gall-bladder was completely closed and the wound soundly united. Since then, however, upon two occasions small quantities of clear fluid have been discharged from the wound. On the last occasion, the tenth day after operation, the fluid was slightly tinged with bile, and since then the wound has remained perfectly healed, and no tumour is to be felt, the patient being in all respects perfectly well.

May 8th-A very good report was received from her mother. 'The patient was steadily gaining strength, and was free from pain.

P.S.- The putty-like contents of the gall-bladder, when examined under the microscope, exhibited innumerable crystals of mono-calcic phosphate. No erystals of cholesterin were found. The gallstones were composed chiefly of cholesterin. 